Research Article

\title{
Analysis of the Mechanical Properties and Mechanism of Zinc Ion-Contaminated Red Clay
}

\author{
Jiaming Li, ${ }^{1}$ Shibin Tang ${ }^{(D},{ }^{1}$ and Xuejun Chen ${ }^{2}$ \\ ${ }^{1}$ School of Civil Engineering, Dalian University of Technology, Dalian 116024, China \\ ${ }^{2}$ College of Civil Engineering and Architecture, Guilin University of Technology, Guilin 541004, China \\ Correspondence should be addressed to Shibin Tang; tang_shibin@dlut.edu.cn
}

Received 8 October 2020; Revised 25 December 2020; Accepted 15 January 2021; Published 25 January 2021

Academic Editor: Victor M. Castaño

Copyright (c) 2021 Jiaming Li et al. This is an open access article distributed under the Creative Commons Attribution License, which permits unrestricted use, distribution, and reproduction in any medium, provided the original work is properly cited.

To study the effects of different concentrations of zinc ions on the mechanical strength, material composition, and microstructure of red clay, a triaxial test, an x-ray diffraction test, an x-ray fluorescence spectrometry test, a scanning electron microscopy test, and a mercury intrusion test were carried out on contaminated soil to investigate the mechanisms of zinc ion-contaminated red clay. The results show that the higher the concentration of zinc ions, the smaller the shear strength and cohesion of the red clay. The internal friction angle is increased first and then decreased. From material composition, zinc ion makes montmorillonite and hemite disappear in red clay. With the increase of zinc ion concentration, quartz semiquantitative increase and kaolinite semiquantitative decrease and the content of $\mathrm{SiO}_{2}, \mathrm{Fe}_{2} \mathrm{O}_{3}$, and $\mathrm{Na}_{2} \mathrm{O}$ reduces. Microscopically, the structure of red clay changes from floc structure to granular and aggregate structure after the zinc ions are added, while the contact of the particles is converted to point contact. With the increase of the concentration of zinc ions, the porosity and the fractal dimension of the red clay gradually increase, and the stability of the granular structure is weakened.

\section{Introduction}

Red clay is widely distributed in the Sichuan, Yunnan, Guizhou, Hunan, and Guangxi provinces in China. It is a material with a high void ratio, high dispersion, high strength, high water content, and low compressibility [1]. Red clay accounts for approximately $75 \%$ of the whole quaternary distribution area in Guilin, China [2]. In recent years, the development of the mining industry has resulted in serious heavy metal pollution in this area. Heavy metal ions change the structure of red clay, resulting in the variation in its mechanical properties, often leading to slope instability, pavement cracking, and uneven settlement of foundations [3].

Regarding the pollution of heavy metals in soil, most scholars focus on expansive soil [4], bentonite [5], kaolin, and montmorillonite $[6,7]$. There are a few reports on the effect of heavy metal ions on red clay. Zhang et al. [8] mixed red clay contaminated with heavy metal ions with cement, fly ash, and quicklime and then studied the effects of different concentrations of sulfate and different erosion time conditions on the strength and leaching characteristics of contaminated red clay. Li et al. [9] studied the relationship between soil characteristics and heavy metal accumulation in the red clay layer and proved that aluminosilicate and oxides adsorbed heavy metals in the red clay. They found that weather and soil formation in the source region are important driving forces for the change in the heavy metal content in red clay. Bocanegra et al. [10] used calcium carbonate and organics to solidify heavy metal ions in red clay, changing the plasticity of the red clay and degassing process during sintering. Agwaramgbo et al. [11] used red clay to adsorb lead in polluted water and achieved a good remediation effect. Gładysz-Płaska et al. [12] used modified red clay to adsorb chromium and phenol and obtained the absorption law with parameters such as temperature, $\mathrm{pH}$, ionic strength, and initial adsorption ion concentration for phenol and chromium ions. Gładysz-Płaska et al. [13] carried out absorption studies of uranium (VI) and phosphate in red clay and obtained the 
results that, in the presence of phosphate, the adsorption of uranium (VI) is mainly carried out by surface complexation or surface precipitation, and the participation of the ion exchange is small. However, most of the previous studies focused on the adsorption of heavy metal ions by red clay and the solidification of heavy metal ions in red clay but ignored the effect of heavy metal ions on the mechanical properties of red clay.

Due to the rich zinc resources in Guilin and serious zinc ion pollution in some building areas, the $\mathrm{SO}_{4}^{2-}$ anion experiences physical adsorption, with little effect on the water absorption capacity of red clay [14]. Therefore, in this paper, zinc sulfate was selected as the pollutant of the red clay. A triaxial shear test, $\mathrm{x}$-ray diffraction test (XRD), $\mathrm{x}$-ray fluorescence spectrum analysis test (XRF), scanning electron microscope test (SEM), and mercury injection test (MIP) were carried out in the laboratory. The variation in the mechanical properties of remolded red clay under different zinc ion concentrations and confining pressures was studied by means of the controlling variable method. The effects of zinc ions on the composition and microstructure of red clay materials were analyzed. The microscopic mechanism of the change in the macroscopic mechanical properties of the contaminated soil is discussed.

\section{Materials}

The red clay soil sample used in the test was taken from a construction site in Yanshan District, Guilin City, at a depth of 5-7 m, which is in the upper Pleistocene residual layer $\left(Q_{3}^{\mathrm{el}}\right)$, and was brownish red. The soil has good representativeness and is relatively uniform and highly viscous. The cross section of the soil is smooth, soft, and plastic, the cracks are not developed, and there are no gravel particles. The exact sampling location of the red clay is shown in Figure 1. The basic physical properties are shown in Table 1 . The relative molecular weight of the pollution source $\mathrm{ZnSO}_{4} \cdot 7 \mathrm{H}_{2} \mathrm{O}$ is 287.58 , and its content is more than $99.5 \%$. The $\mathrm{pH}$ value $\left(50 \mathrm{~g} / \mathrm{L}, 25^{\circ} \mathrm{C}\right)$ is $4.4-6.0$, the relative density is 1.957 , and the melting point is 100 of the white prismatic crystal. The stable hydrate balanced with water at a range of $0 \sim 39^{\circ} \mathrm{C}$ is gradually weathered in dry air and is irritated. $\mathrm{ZnSO}_{4} \cdot 7 \mathrm{H}_{2} \mathrm{O}$ has high solubility and fast dissolution rate and is easily soluble in water, but slightly soluble in alcohol and glycerol, and the solution is colorless and transparent.

\section{Effect of Zinc Ions on the Mechanical Properties of Red Clay}

According to the geotechnical standard test method [15], the red clay soil sample retrieved was air-dried, crushed, sieved through a $2 \mathrm{~mm}$ sieve, and dried. The zinc sulfate solution was prepared with distilled water to make the zinc ion concentrations (zinc ion concentration is the mass ratio of zinc ions to soil particles) of $0 \%, 0.1 \%, 0.2 \% 0.5 \%$, and $1.0 \%$, respectively, and then sprayed with water according to $30 \%$ of the optimal moisture content of red clay obtained from the compaction test. The solution was stirred evenly and sealed and allowed to stand for 24 hours. Then, the mass of the red clay was weighed according to a dry density of $1.35 \mathrm{~g} /$ $\mathrm{cm}^{3}$, and the triaxial test sample was prepared by means of the compaction method. The sample is $80.0 \mathrm{~mm}$ in height and $39.1 \mathrm{~mm}$ in diameter. Then, the sample was vacuumed and saturated.

The test instrument was the TSZ-1 strain gauge triaxial instrument produced by Nanjing Soil Instrument Factory. Under the confining pressure of $100 \mathrm{kPa}, 200 \mathrm{kPa}$, and $300 \mathrm{kPa}$, the undrained consolidation triaxial shear tests with a shear rate of $0.9 \mathrm{~mm} / \mathrm{min}$ were carried out. The tests were terminated when the axial strain reached $15 \%$. The failure state of red clay samples with different zinc ion concentrations is shown in Figure 2. It can be seen that the red clay samples with different zinc ion concentrations are dilatancy failure. For the undrained test, it is mainly considered that the zinc ions will flow out with the discharged pore water in the drainage process, which leads to the uncontrollable discharge of zinc ions and changes the initial variable of the experiment. The peak of the deviatoric stress on the stressstrain curve was taken as the failure point and when there was no peak, the point on the curve corresponding to the axial strain of $15 \%$ was taken as the failure point. The Mohr circle was drawn based on the condition that the normal stress was the abscissa and the shear stress was the ordinate, and the common tangent was used to obtain the cohesion and internal friction angle. Finally, the shear strength was calculated according to the Mohr-Coulomb strength criterion, as shown in (1). The calculation results of the shear strength and shear strength index are shown in Table 2, and the fitting curve is shown in Figure 3.

$$
\tau_{f}=c+\sigma \tan \phi
$$

where $c$ is the cohesion and $\phi$ is the internal friction angle.

It can be seen from Figures 3(a) and 3(b) that the fitting function of shear strength and cohesion with zinc ion concentration is $y=a^{*} \exp (-x / b)+c(x$ is the concentration of zinc ions; $y$ is shear strength or cohesion; and $a, b, c$ are constants), and the fitting coefficient is quite large. When $x=0, y=a+c$, the red clay is not contaminated by zinc ions, and the shear strength or cohesion is $a+c$. Under different experimental conditions, the values of $a$ and $c$ will change, and the shear strength and cohesion will also change. When $x \longrightarrow 1$, thus $y$ approaches $a^{*} \exp (-1 / b)+c$. That is, when the critical value of zinc ion concentration is exceeded, the change in the zinc ion concentration has little effect on the shear strength and cohesion of red clay, and the critical value of the zinc ion concentration is approximately $0.2 \%$. In addition, the shear strength is proportional to the confining pressure (Figure 4), and the shear strength increases incrementally with the increase in the radial confining pressure, and the variation in shear strength with zinc ion concentration is approximately the same under different confining pressures. Under the same confining pressure, with the increase in zinc ion concentration, the shear strength first decreases rapidly, and when the zinc ion concentration reaches $0.2 \%$, the shear strength decreases gradually and finally tends to be stable. The variation in cohesion with zinc ion concentration is consistent with the shear strength. The 


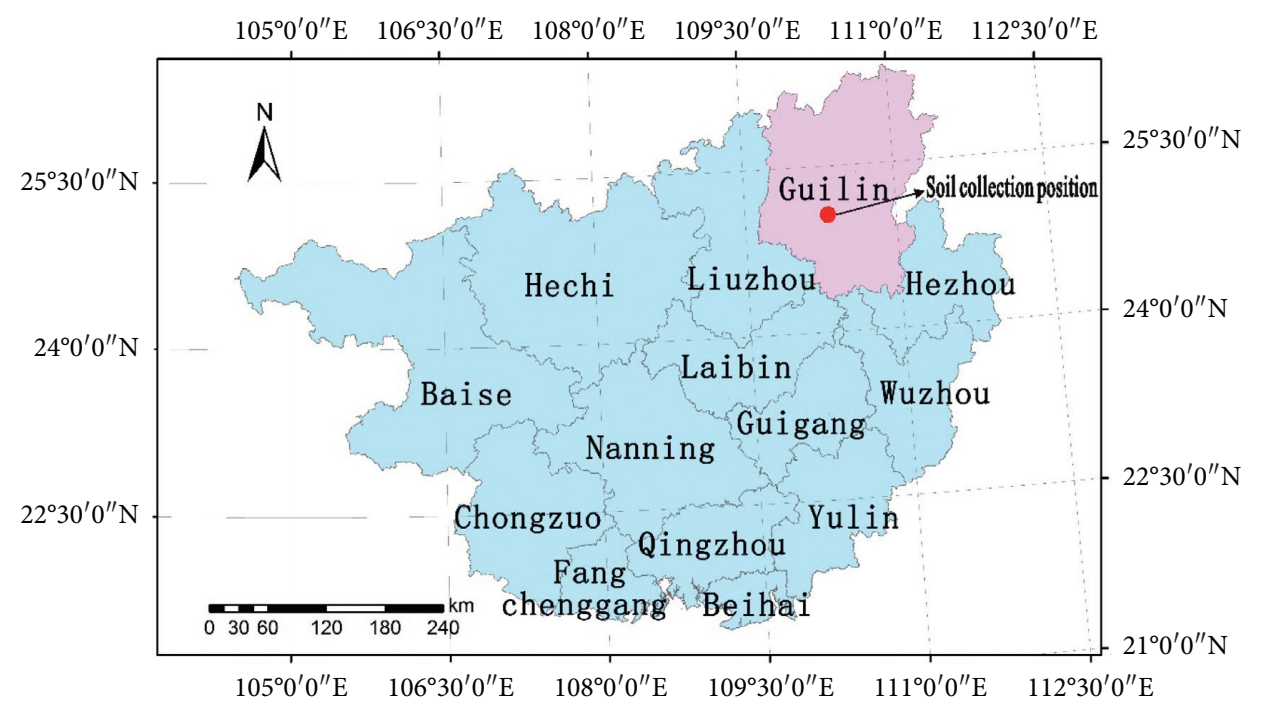

FIgURE 1: Schematic diagram of the soil extraction position.

TABle 1: Basic physical properties of red clay.

\begin{tabular}{lccccc}
\hline $\begin{array}{l}\text { Liquid limit } W_{L} \\
(\%)\end{array}$ & $\begin{array}{c}\text { Plastic limit } W_{p} \\
(\%)\end{array}$ & $\begin{array}{c}\text { Plasticity index } \\
I_{P}\end{array}$ & $\begin{array}{c}\text { Optimum water content } \omega \\
(\%)\end{array}$ & $\begin{array}{c}\text { Maximum dry density } \rho_{d} \\
\left(\mathrm{~g} \cdot \mathrm{cm}^{-3}\right)\end{array}$ & $\begin{array}{c}\text { Relative density } \\
d_{s}\end{array}$ \\
\hline 62.9 & 43.1 & 19.8 & 30 & 1.575 & 2.7 \\
\hline
\end{tabular}

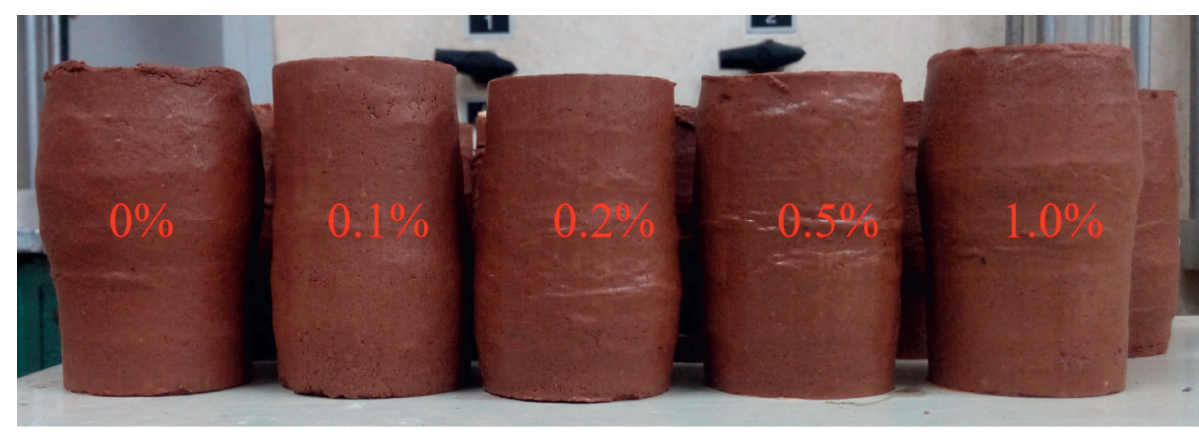

FIGURE 2: Failure state of red clay samples under different zinc ion concentrations.

TABLE 2: Shear strength and shear strength index.

\begin{tabular}{lccccc}
\hline Zinc ion concentration (\%) & \multicolumn{3}{c}{ Shear strength $(\mathrm{kPa})$} & Cohesion $c$ & Internal friction angle $\phi\left({ }^{\circ}\right)$ \\
\hline 0 & $100 \mathrm{kPa}$ & $200 \mathrm{kPa}$ & $300 \mathrm{kPa}$ & 44.20 & 13.32 \\
0.1 & 84.48 & 110.89 & 142.55 & 13.48 & 14.11 \\
0.2 & 47.47 & 80.48 & 109.91 & 9.49 & 13.88 \\
0.5 & 42.62 & 72.61 & 103.89 & 9.22 & 13.27 \\
1 & 40.40 & 69.21 & 98.40 & 7.8 & 12.75 \\
\hline
\end{tabular}

internal friction angle first increases and then decreases with increasing zinc ion concentration (Figure 3(c)). The clay mineral surface is negatively charged, and when the zinc ion concentration is $0 \sim 0.1 \%$, the attraction between the zinc ion and the clay mineral decreases the thickness of the electric double layer, the distance between the soil particles becomes smaller, and the bite force increases, so the internal friction angle increases. When the concentration of zinc ion is increased, the crystal water will be diluted when the solution is mixed with red clay, which destroys the structure of red clay and reduces the friction between soil particles, so the internal friction angle decreases. 


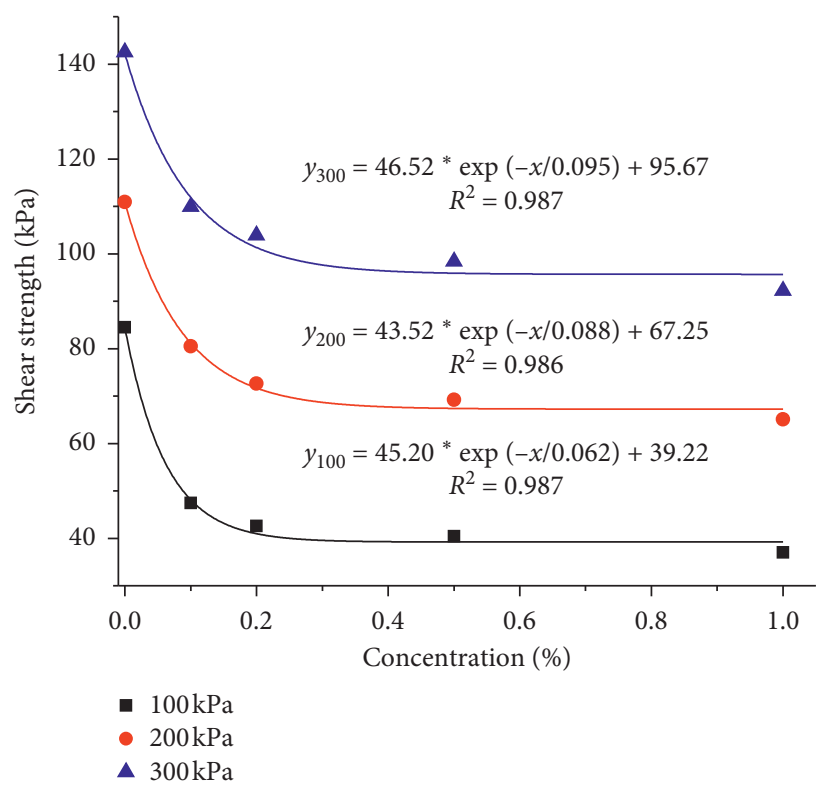

(a)

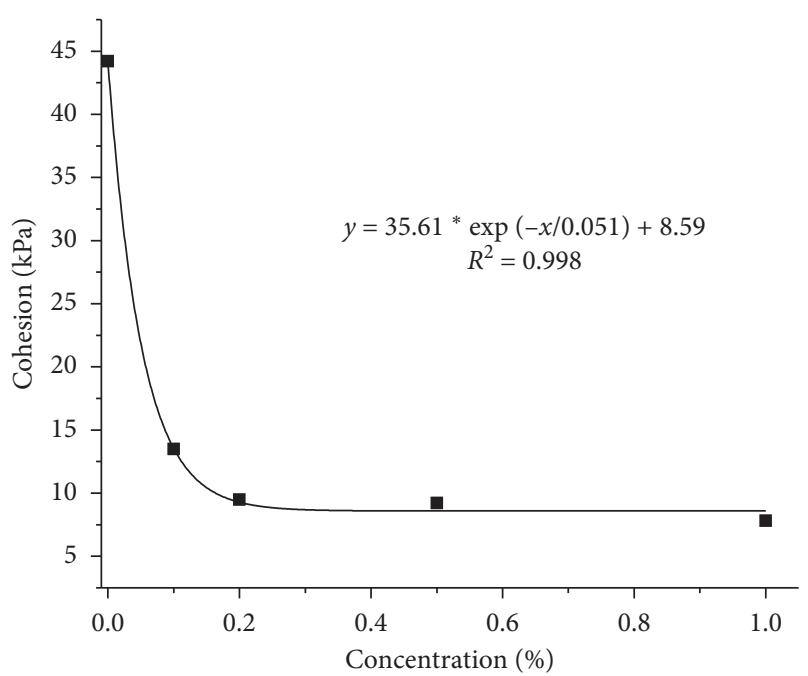

(b)

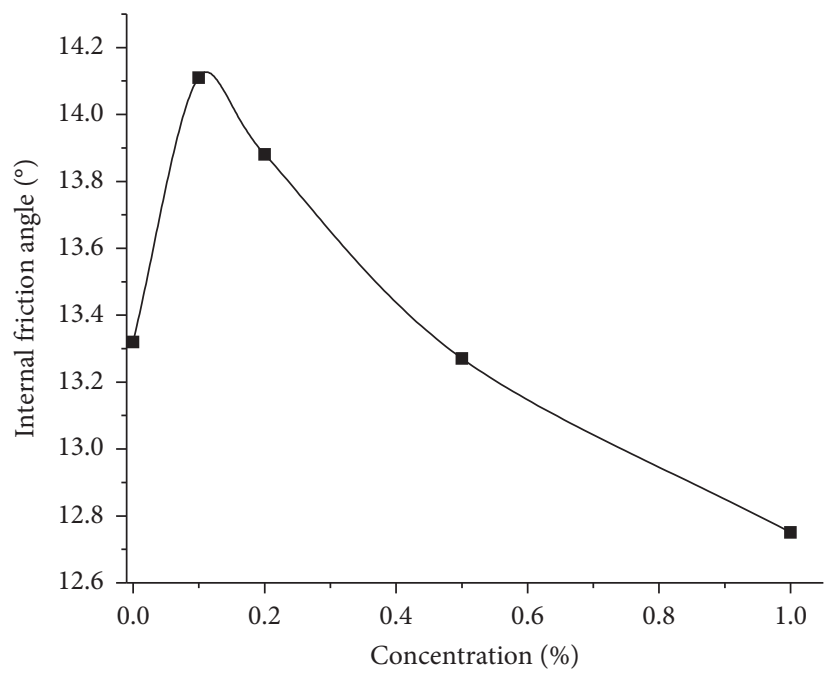

(c)

FIGURE 3: Relationship curves between zinc ion concentration and shear strength index. (a) Fitting curve of the relationship between zinc ion concentration and shear strength. (b) Fitting curve of the relationship between zinc ion concentration and cohesion. (c) Curve of the relationship between zinc ion concentration and internal friction angle.

\section{Effect of Zinc Ions on the Composition of Red Clay}

The contaminated soil used in the triaxial test was crushed and dried after passing through a $0.075 \mathrm{~mm}$ sieve. X-ray diffraction tests (XRD) and X-ray fluorescence spectrometry (XRF) were carried out to study the influence of zinc ion soil on the mineral and chemical composition of red clay.

The XRD test used the $\mathrm{X}^{\prime}$ PertPRO $\mathrm{x}$-ray diffractometer manufactured by PANalytical B.V. of the Netherlands [16]. The initial angle was $10^{\circ}$, the end angle was $80^{\circ}$, and the test data was processed by $\mathrm{X}^{\prime}$ Pert HighScorer software. According to the "three-peak method," the mineral components were qualitatively and quantitatively analyzed. As the $\mathrm{x}$-ray diffraction patterns of red clay with $0.1 \%, 0.2 \%$, $0.5 \%$, and $1.0 \%$ zinc ions were similar, $\mathrm{x}$-ray diffraction patterns were taken as examples of $0 \%$ and $0.1 \%$, as shown in Figures 5(a) and 5(b), for each mineral. The semiquantitative results are shown in Table 3; the XRF test equipment used the ZSX Primus II X-ray fluorescence spectrometer produced by Rigaku Corporation of Japan. The variation law of the oxide percentage content in the soil sample is shown in Table 4.

The mineral components of the red clay obtained in the XRD test were mainly quartz, kaolinite, montmorillonite, and hematite. After adding zinc ions, the montmorillonite and hematite disappeared, and the content of quartz and kaolinite increased. As the concentration of zinc ions 


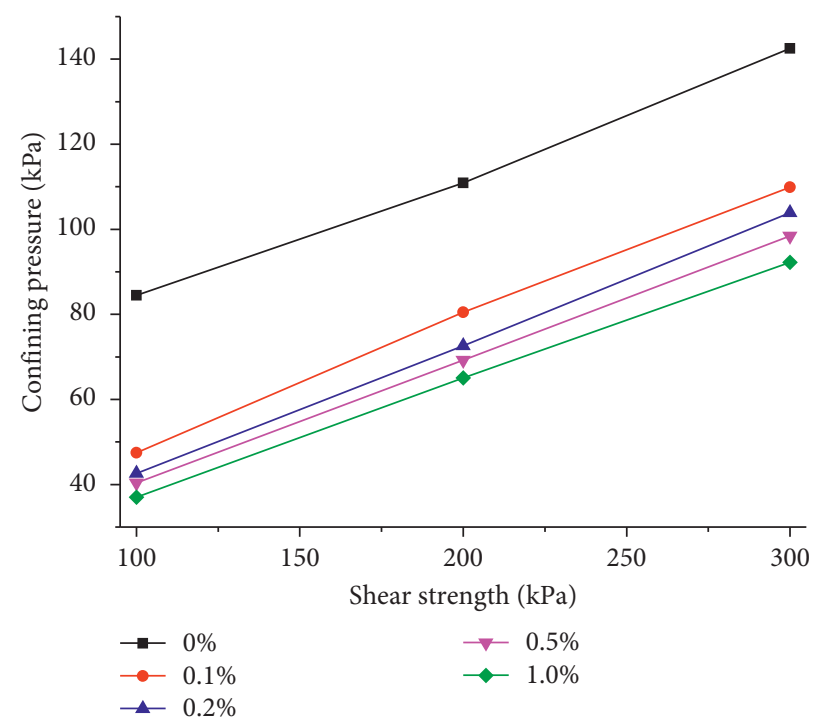

FIGURE 4: The curves between shear strength and confining pressure under different zinc ion concentrations.

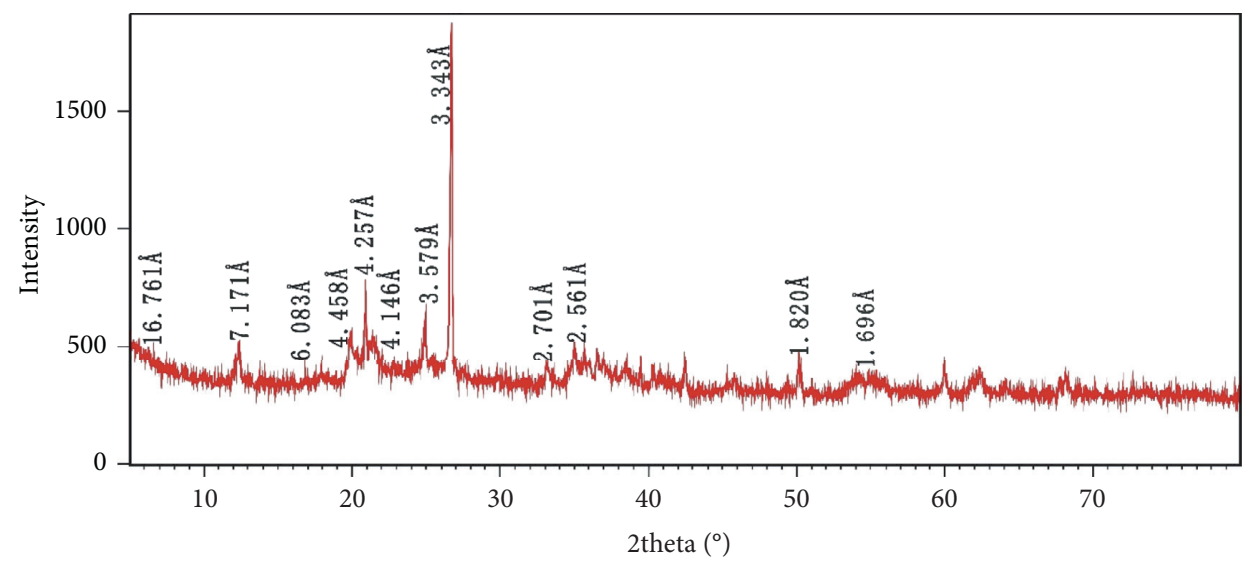

(a)

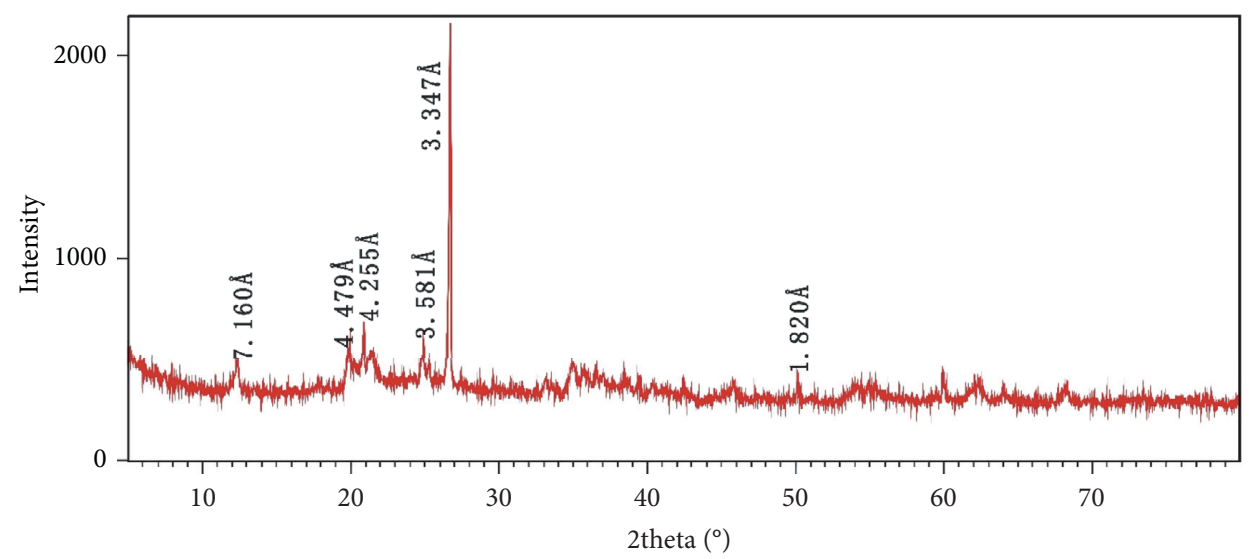

(b)

FIgURE 5: X-ray diffraction spectrum. (a) The x-ray diffraction pattern of red clay. (b) The x-ray diffraction pattern of red clay with a zinc ion concentration of $0.1 \%$. 
TABLE 3: Semiquantitation of the minerals.

\begin{tabular}{lcccc}
\hline Concentration & \multicolumn{3}{c}{$\begin{array}{c}\text { Semiquantitative mineral composition (\%) } \\
\text { Montmorillonite }\end{array}$} \\
\hline 0 & Quartz & 22 & 10 & \\
0.1 & 55 & 29 & $0 \%$ & $0 \%$ \\
0.2 & 71 & 28 & $0 \%$ & $0 \%$ \\
0.5 & 72 & 24 & $0 \%$ & $0 \%$ \\
1 & 76 & 23 & $0 \%$ & $0 \%$ \\
\hline
\end{tabular}

TABLE 4: Oxide content of the soil sample.

\begin{tabular}{lcccccccccc}
\hline Zinc ion concentration (\%) & $\begin{array}{c}\mathrm{SiO}_{2} \\
\text { mass (\%) }\end{array}$ & $\begin{array}{c}\mathrm{Al}_{2} \mathrm{O}_{3} \\
\text { mass (\%) }\end{array}$ & $\begin{array}{c}\mathrm{Fe}_{2} \mathrm{O}_{3} \\
\text { mass (\%) }\end{array}$ & $\begin{array}{c}\mathrm{TiO}_{2} \\
\text { mass (\%) }\end{array}$ & $\begin{array}{c}\mathrm{K}_{2} \mathrm{O} \\
\text { mass (\%) }\end{array}$ & $\begin{array}{c}\mathrm{CaO} \\
\text { mass (\%) }\end{array}$ & $\begin{array}{c}\mathrm{MgO} \\
\text { mass (\%) }\end{array}$ & $\begin{array}{c}\mathrm{Na}_{2} \mathrm{O} \\
\text { mass (\%) }\end{array}$ & $\begin{array}{c}\mathrm{P}_{2} \mathrm{O}_{5} \\
\text { mass (\%) }\end{array}$ & $\begin{array}{c}\mathrm{MnO}^{2} \\
\text { mass (\%) }\end{array}$ \\
\hline 0 & 44.129 & 26.408 & 16.835 & 2.062 & 1.836 & 1.598 & 0.383 & 0.221 & 0.096 & 0.016 \\
0.1 & 44.079 & 26.652 & 16.771 & 2.085 & 1.851 & 1.590 & 0.388 & 0.219 & 0.098 & 0.014 \\
0.2 & 44.068 & 26.459 & 16.708 & 2.088 & 1.844 & 1.592 & 0.392 & 0.215 & 0.096 & 0.014 \\
0.5 & 43.969 & 26.136 & 16.544 & 2.043 & 1.804 & 1.592 & 0.397 & 0.208 & 0.096 & 0.014 \\
1.0 & 43.569 & 25.866 & 16.506 & 1.995 & 1.804 & 1.590 & 0.362 & 0.177 & 0.091 & 0.014 \\
\hline
\end{tabular}

increased, the content of quartz increased and the content of kaolinite decreased. According to the XRF test results, the main chemical components of the red clay included $\mathrm{SiO}_{2}$, $\mathrm{Al}_{2} \mathrm{O}_{3}, \mathrm{Fe}_{2} \mathrm{O}_{3}, \mathrm{TiO}_{2}, \mathrm{~K}_{2} \mathrm{O}, \mathrm{CaO}, \mathrm{MgO}, \mathrm{Na}_{2} \mathrm{O}, \mathrm{P}_{2} \mathrm{O}_{5}$, and $\mathrm{MnO}$. The contents of $\mathrm{SiO}_{2}, \mathrm{Al}_{2} \mathrm{O}_{3}$, and $\mathrm{Fe}_{2} \mathrm{O}_{3}$ were as high as $87.195 \%$. The content of oxides changed after adding zinc ions. With increasing zinc ion concentration, the contents of $\mathrm{SiO}_{2}, \mathrm{Fe}_{2} \mathrm{O}_{3}, \mathrm{Na}_{2} \mathrm{O}$, and $\mathrm{CaO}$ decreased gradually, and the contents of $\mathrm{Al}_{2} \mathrm{O}_{3}, \mathrm{TiO}_{2}$, and $\mathrm{K}_{2} \mathrm{O}$ first increased and then decreased.

\section{Effect of Zinc Ions on the Microstructure of Red Clay}

The study of the soil microstructure mainly focused on the shape, composition, and arrangement of particles inside the soil, as well as the crystal shape and distribution of minerals and the plastic mold properties of the surface of the structure. Electron microscopy images were used to intuitively and qualitatively analyze the pore size distribution in the soil, and the mercury intrusion test was conducted to quantitatively investigate the distribution of pores in the soil. Therefore, the combination of electron microscopy (SEM) and the mercury intrusion test (MIP) were effective methods for studying the microstructure of the soil.

5.1. Scanning Electron Microscopy Test. The instrument used in this test was the S-4800 field emission scanning electron microscope produced by Japan Hi-Tech Co., Ltd. The maximum accelerating voltage is $30 \mathrm{kV}$, the maximum magnification is up to 800,000 times, the point resolution is $0.19 \mathrm{~nm}$, and the line resolution is $0.14 \mathrm{~nm}$. The contaminated soil was made into a soil sample with a dry density of $1.35 \mathrm{~g} / \mathrm{cm}^{3}$ and subjected to electron microscopy scanning. The magnification was 3000 times, and the test results are shown in Figure 6.

The contact forms of the clay particles were point contact, edge contact, surface contact, and inlaid contact.
It can be seen from Figure 6(a) that the main structure of the red clay particles was a laminar, flat-shaped particle aggregate with surface contact between the units, together with a flocculation structure with surface or point contact, and the superposition of the aggregates was tightly superimposed with fewer fractures and micropores than when the clay contains zinc ions. When $0.1 \%$ (Figure 6(b)) and $0.2 \%$ (Figure $6(\mathrm{c})$ ) zinc ions were added, the pore and particle arrangements of the red clay were observed. Changes occurred, and cracks and pores gradually increased. When the concentration of zinc ions was $0.2 \%$, the development of cracks was clearly visible. When the concentration of zinc ions reached within the range of $0.5 \%$ (Figure $6(\mathrm{~d})$ ) to $1.0 \%$ (Figure 6(e)), the structural changes of the red clay were quite obvious, mainly composed of agglomerates and flaky particles, which were bonded together by the cementing material in the form of a hill shape, and open pores were observed. The aggregates mainly consisted of granules and flaky particles, and the aggregated arrangement was nonoriented. The size of the particles was different, and the bond between the clay particles was very loose. The edge of the soil particles was obvious, and the contact form was mostly point contact. The contact area between the soil particles per unit volume was reduced, and the pores and cracks were extremely developed.

Taking the zinc ion concentration of $0.2 \%$ as an example (Figure 7(a)), the original image obtained by SEM is transformed into grayscale image by MATLAB, then edge detection is carried out, and the corresponding threshold is set by threshold segmentation method, which makes the original grayscale image into binary image (Figure $7(b)$ ). After processing, there are only two colors: black and white, black area represents pores, white area represents red clay particles, and the porosity is calculated by the proportion of black and white pixels. The data of the SEM images processed by MATLAB is shown in Table 5. The curve of the relationship between zinc ion concentration and porosity and fractal dimension is shown in Figure 8. 


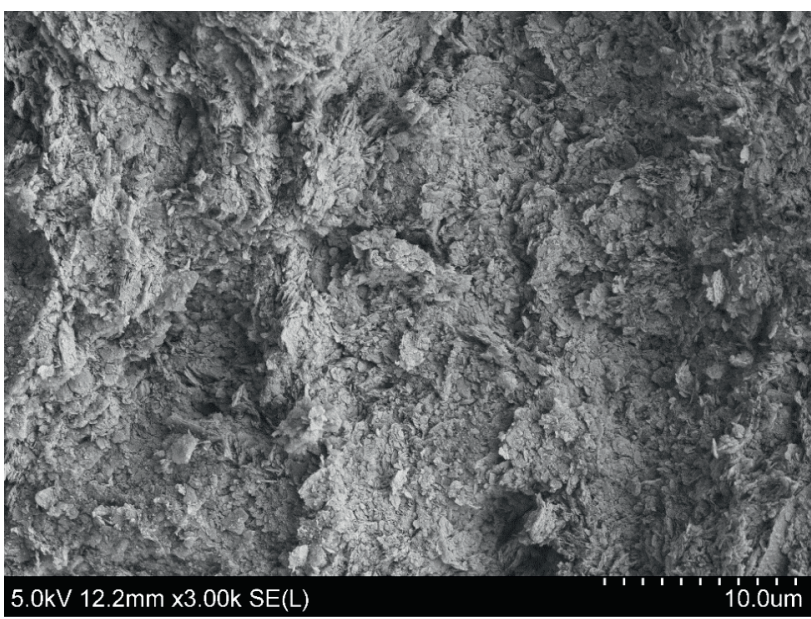

(a)

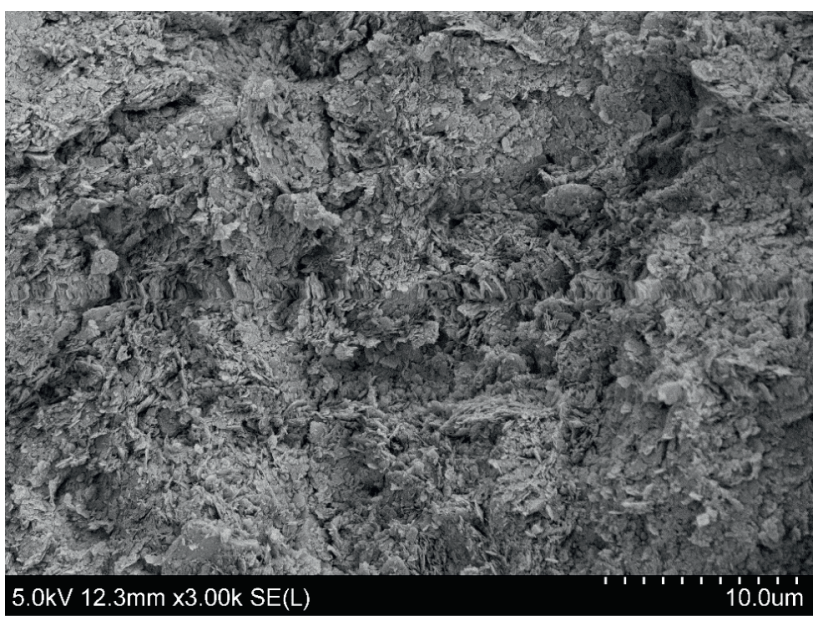

(c)

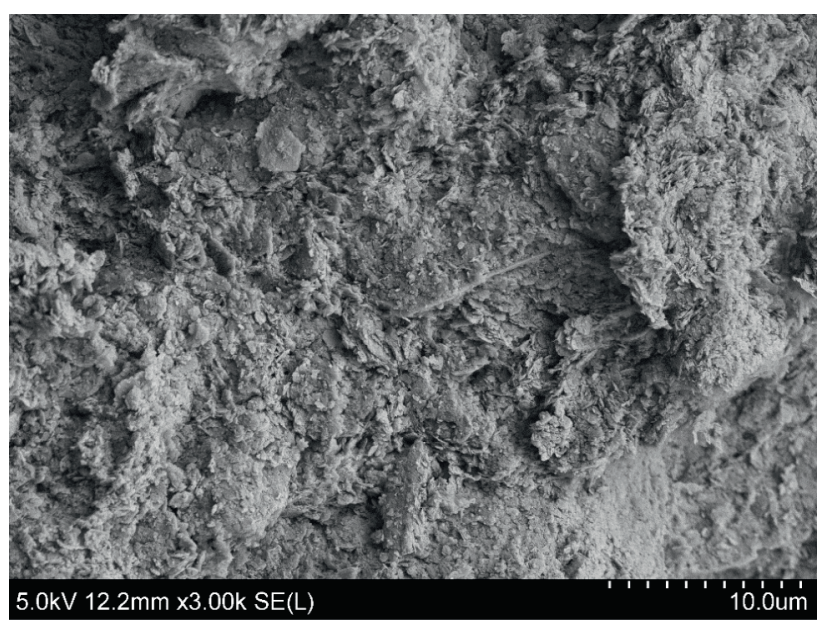

(b)

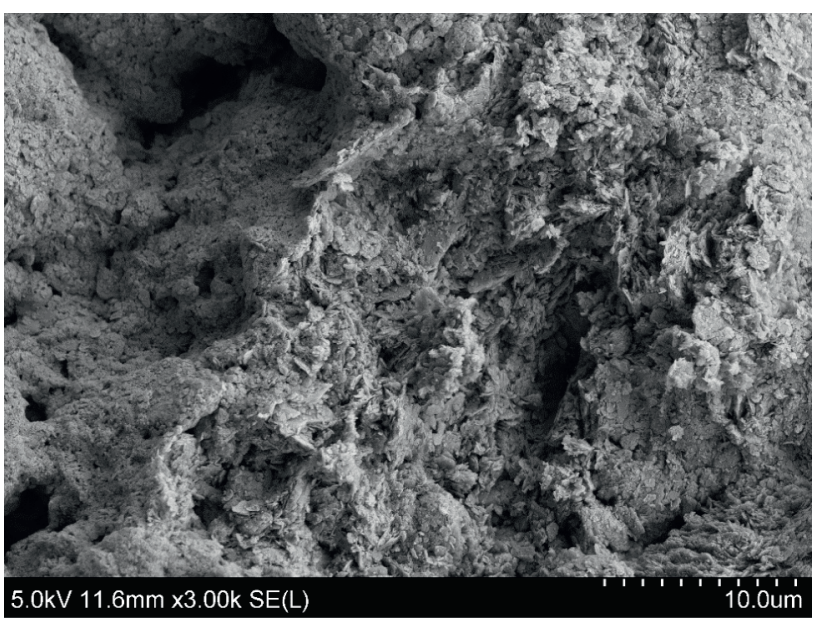

(d)

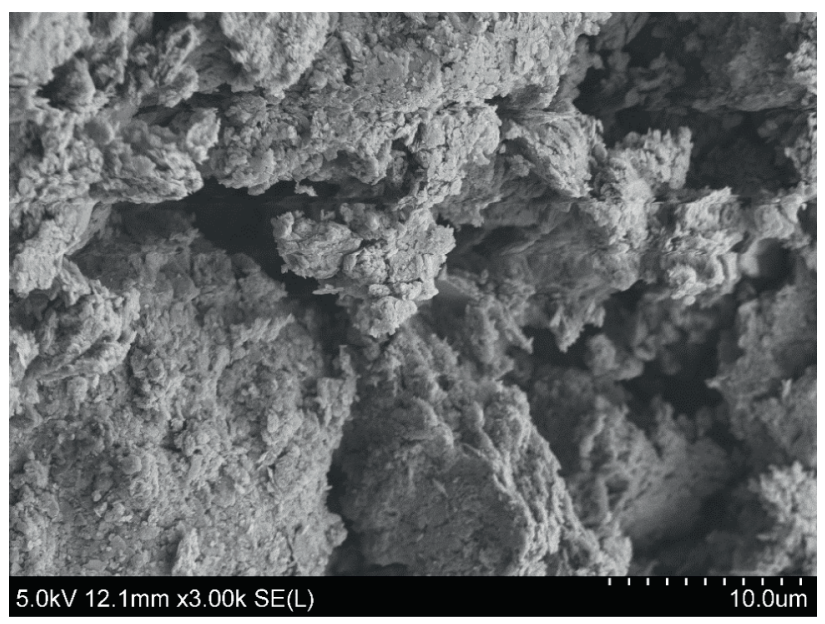

(e)

Figure 6: Microstructure of remolded red clay under different zinc ion concentrations. (a) Zinc ion concentration of $0 \%$. (b) Zinc ion concentration of $0.1 \%$. (c) Zinc ion concentration of $0.2 \%$. (d) Zinc ion concentration of $0.5 \%$. (e) Zinc ion concentration of $1.0 \%$. 


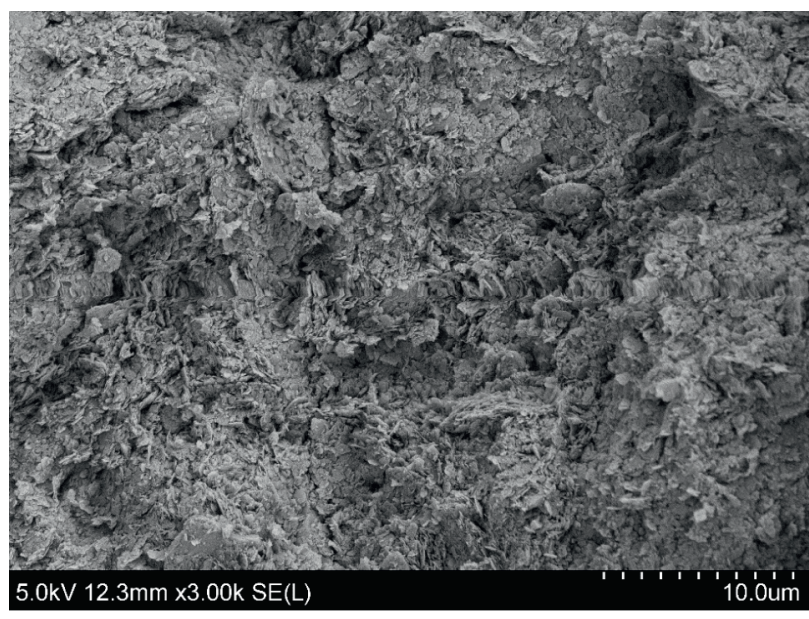

(a)

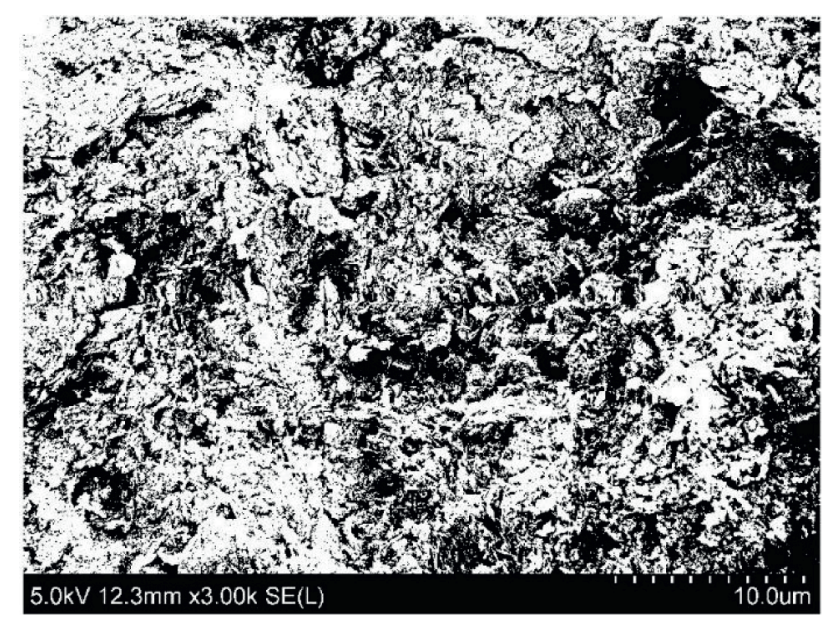

(b)

FIGURE 7: Original image and binary image. (a) Original image. (b) Binary image.

TABLE 5: Processing image data by MATLAB analysis.

\begin{tabular}{lccc}
\hline Concentration (\%) & Porosity & $\begin{array}{c}\text { Fractal } \\
\text { dimension }\end{array}$ & Fitting coefficient \\
\hline 0 & 0.4632 & 1.7639 & 0.9995 \\
0.1 & 0.4696 & 1.7706 & 0.9999 \\
0.2 & 0.5442 & 1.7748 & 0.9991 \\
0.5 & 0.5628 & 1.8360 & 0.9999 \\
1.0 & 0.5801 & 1.8609 & 0.9997 \\
\hline
\end{tabular}

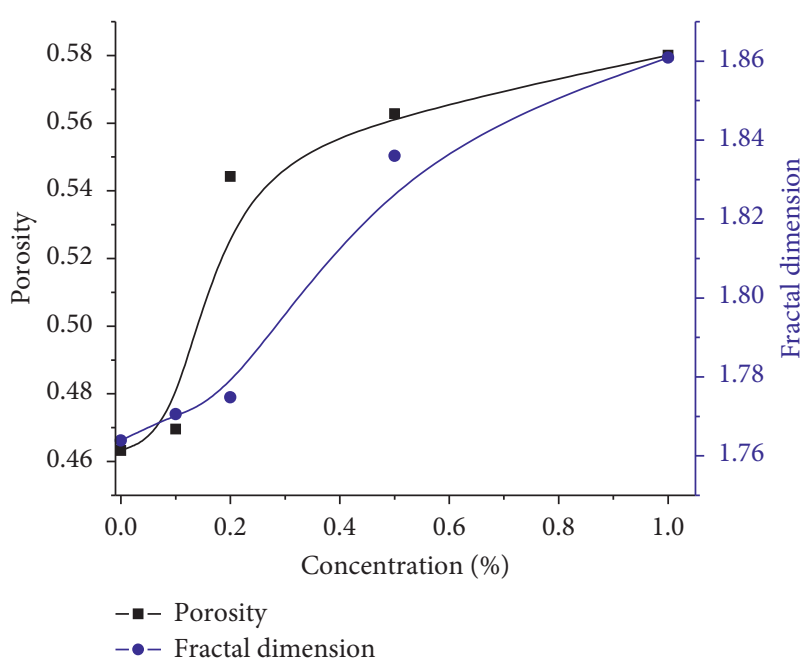

FIGURE 8: Relationship curve of zinc ion concentration with porosity and fractal dimension.

In general, the fractal dimension can be used to describe the roughness or complexity of the surface of soil samples. For larger fractal dimensions, the pore development of the red clay was more obvious, the structure was more complex, the surface was rougher, and the degree of dispersion was higher. It can be seen from the MATLAB analysis of the SEM images that the porosity and fractal dimension of the remodeled red clay were proportional to the zinc ion concentration after being contaminated by zinc ions. As the zinc ion concentration increased, the porosity and fractal dimension increased, the distribution area and dispersion of the pores became larger, and the soil was looser.

5.2. Mercury Intrusion Test. The principle of the mercury intrusion test is that the applied pressure and the cylindrical pore radius satisfy the Washburn equation [17]. The pore model where liquid mercury was injected could be expressed in

$$
P=\frac{2 T_{s} \cos \theta}{r},
$$

where $P$ is the applied pressure; $T_{s}$ is the surface tension coefficient of the introduced liquid; $\theta$ is the contact angle of the liquid with the solid material; and $r$ is the radius of the equivalent pore.

Equation (2) shows that a greater pressure will push a more sufficient amount of mercury to enter the pores of the soil. By measuring the amount of mercury that entered the pores, the equivalent volume of the corresponding pores was evaluated. The red clay samples contaminated with different zinc ions were cut into strips with the size of $1 \mathrm{~cm} \times$ $1 \mathrm{~cm} \times 2 \mathrm{~cm}$, frozen in liquid nitrogen, and dried in a quick freeze dryer for 24 hours. The test instrument was a POREMASTER33 GT automatic mercury intrusion meter produced by Conta Instruments, as shown in Figure 9. The test pressure range was from $140 \mathrm{kPa}$ to $231 \mathrm{MPa}$, and the curve of the increment of $V$ (injected mercury) versus the $\log$-increment of $D$ (diameter of the pores) was obtained based on the test results, as shown in Figure 10.

The relationship between mercury intrusion and pore distribution could be obtained by the mercury intrusion experiment. Figure 10 intuitively reflected the distribution of the pore size of the measured soil sample. The pores in red clay were irregularly connected or closed, and the pore size distribution was relatively uniform, mainly concentrated in small voids of $0.007 \mu \mathrm{m}<d<0.1 \mu \mathrm{m}$ and large pores of 


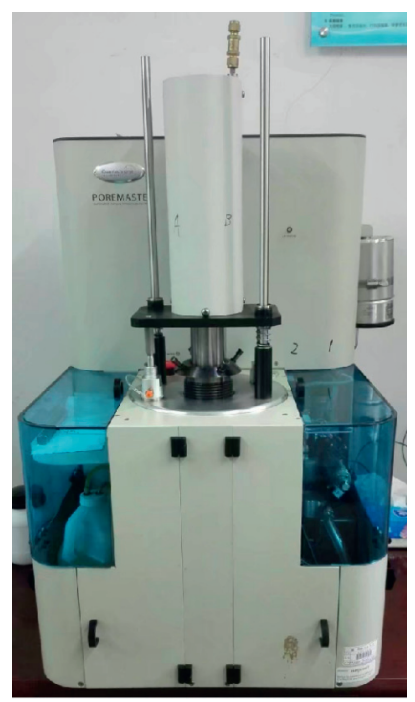

Figure 9: Mercury porosimeter.

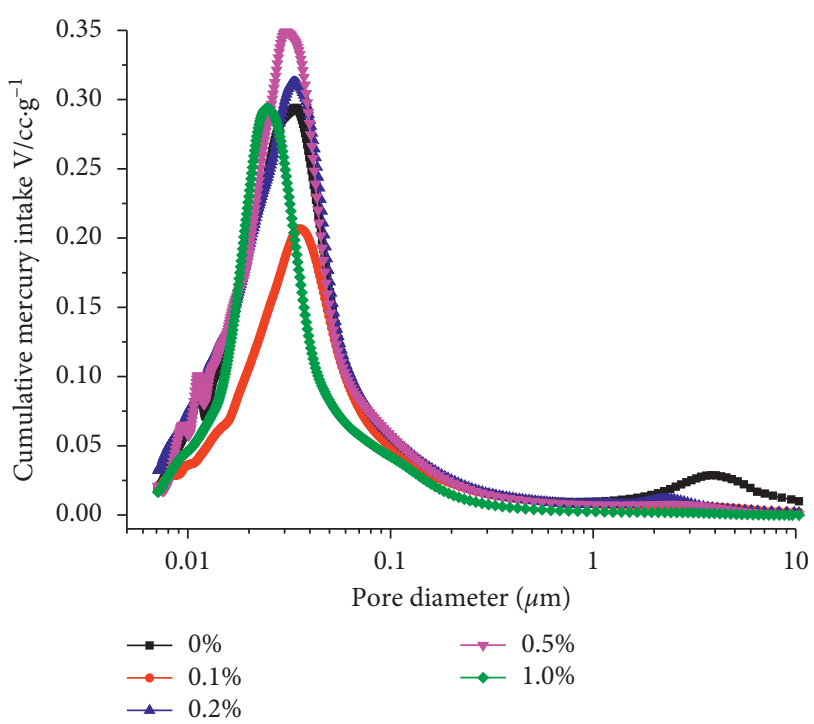

FIGURE 10: Relationship between aperture and cumulative mercury intrusion.

$1 \mu \mathrm{m}<d<10 \mu \mathrm{m}$. More mercury entered the pores with voids of $0.007-0.1 \mu \mathrm{m}$, indicating that the red clay was mainly composed of small pores. After adding zinc ions, the peak shape and position of the large and small pores of the red clay did not change much, and the large pores decreased. When the concentration of zinc ions was $0.1 \%$, the small pores of the red clay decreased, possibly due to the increased content of quartz, kaolinite, $\mathrm{Al}_{2} \mathrm{O}_{3}$, or $\mathrm{K}_{2} \mathrm{O}$. When the concentration of zinc ions was $0.2 \%$ and $0.5 \%$, the small pores of red clay increased, and a higher concentration of zinc ions resulted in the more pores. When the concentration of zinc ions increased to $1 \%$, the small pores of the red clay showed a decreasing trend. That is, as the concentration of zinc ions increased, the small pores of the red clay first decreased and then increased and then decreased.

The variation in the small pores with zinc ion concentration in red clay corresponds to the variation in the internal friction angle. When the concentration of zinc ions is from $0 \%$ to $0.1 \%$, the small pores of the red clay decrease and the corresponding internal friction angle increases, and when the concentration of zinc ions continues to increase, the small pores of the red clay increase and the corresponding internal friction angle decreases. However, when the concentration of zinc ions reaches $1 \%$, both the small pores and internal friction angle show a decreasing trend. It is likely that high concentrations of zinc ions produce large amounts of salts or zinc oxide particles [18], which not only fills the pores but also plays a lubricating role.

\section{Discussion}

In terms of the mineral composition, the behavior of clay depends to a large extent on the type and percentage of minerals in the clay [19]. The surface friction and cementation degree of different types of mineral particles are also very different, mainly because different clay minerals have different particle characteristics, resulting in different specific surface areas, surface microelectric field strengths, and electric double layer water film thicknesses. Furthermore, the surface friction and cementation degree affect the mechanical properties of red clay [20]. Clay minerals have small particle sizes, complex pore structures, strong cation exchange capacities, and large specific surface areas, and most of them have negative charges. Heavy metal ions can be adsorbed by direct binding, surface complexation, and ion exchange. The clay particles have strong physical and chemical interactions with heavy metal ions [21]. The mineral composition of the red clay sample is mainly composed of quartz, kaolinite, montmorillonite, and hematite which is evident by means of the XRD test. Montmorillonite is a 2:1 clay mineral composed of two silica tetrahedrons with alumina octahedron. Kaolinite is a clay mineral with a $1: 1$ structure composed of silica tetrahedron and alumina octahedron. Both montmorillonite and kaolinite belong to silicate and have a unique sheet or layered structure. Quartz, a nonclay mineral, is usually acicular or granular and belongs to a trigonal partial crystal, so the total surface area of montmorillonite and kaolinite is much larger than that of quartz [22]. When zinc ions were added to the red clay, although the semiquantification of kaolinite and quartz increased, montmorillonite and hematite disappeared. The main reason for the decrease in the mechanical properties of the red clay is the disappearance of hematite and the decrease of the free iron oxide cementation between particles. Iron oxide in soil includes crystalline iron and amorphous iron oxide, which have a strong fixation ability [23]. Wang [24] also confirmed through the "iron removal" test that the physical and mechanical properties of laterite will be reduced significantly. With the increase in zinc ion concentration, the content of kaolinite decreases and the content of quartz increases. The clay mineral particles are gradually wrapped by quartz particles, and the van der Waals force of the quartz particles [25] is lower, so its dispersion is higher than that of the clay particles, and the interaction between the quartz particles is defined by physical action, which weakens the adsorption and 
cementation between the particles. The change in mineral content will also reduce the specific surface area of red clay particles, weaken the connection between soil particles, reduce the force between soil particles, and weaken the mechanical properties of red clay.

In terms of the chemical composition, cohesion can be divided into curing cohesion and original cohesion [26]. The content and existing form of cementation in soil determines the magnitude of curing cohesion, such as iron oxide cementation and calcium cementation. The intermolecular force produced by the motion of charged ions determines the original cohesion force, such as an electrostatic force and van der Waals force. The special properties of red clay are mainly caused by the cementation formed by free oxidation. Free iron oxide is distributed in very fine particles on the surface of or among the mineral particles of red clay, and the dispersed soil particles can be cemented together [27]. The clay mineral surface is negatively charged, and part of the free iron oxide is wrapped on the surface of the pellet in the form of a "film," in which this part of the free iron oxide film is positively charged [28]. Because of its large specific surface area and strong interfacial activity, intergranular colloidal iron oxide (amorphous iron) easily forms a sol colloid by means of water. The sol colloid has a strong adsorption ability for zinc ions (but no obvious ion exchange property), which makes the complex formed by amorphous free iron oxide and zinc ions positively charged [29]. This kind of complex is full of particles and repels with the particles, which weakens the connection between the soil particles, disperses easily, and reduces the strength of the red clay. In addition, in the XRF test, as the zinc ion concentration increased, the $\mathrm{Fe}_{2} \mathrm{O}_{3}$ content decreased, the cementation of the soil particles decreased, and the curing cohesion of the red clay decreased. Due to the different valence and concentration of cations, the thickness of the double layer on the surface of the clay, the force of the chemical bond, and the ionic electrostatic force will change, and the thickness of the absorbent film will be different, which will directly affect the properties of the soil [30]. Therefore, the original cohesion can be combined with the diffusion double layer theory to explain the interaction between ions. According to the diffusion double layer (DDL) theory, many chemicals tend to reduce the thickness of the double layer (DDL), which leads to the shrinkage of the soil skeleton, promotes the flocculation of clay particles, and leads to internal dehydration [31]. The thinnest double layer (DDL) structure can be obtained by trivalent cations, followed by divalent cations, and univalent cations have little effect on the thickness of the double layer [32]. There is a negative charge on the surface of clay minerals. When pore water is replaced by a liquid with higher valence zinc ions, clay particles attract zinc ions in water through static electricity, resulting in the accumulation of ions near the double layer (DDL), resulting in a decrease in the thickness of the double layer (DDL). The accumulation of clay particles and the intersection and overlap of the electric double layer DDL lead to a repulsive force between particles [33], reducing the mechanical properties of soil. On the other hand, from Table 4, with the increase in the concentration of zinc ions, the contents of metal cations such as $\mathrm{Fe}^{3+}, \mathrm{Al}^{3+}, \mathrm{Ca}^{2+}, \mathrm{Na}^{+}$, and $\mathrm{K}^{+}$decreased, the ion exchange weakened, and the adsorption connection between particles decreased, thus weakening the original cohesion of the red clay. Wang et al. [34] analyzed the relationship between shear strength, cohesion, internal friction angle, and chemical composition of soil, which is consistent with the experimental results obtained in this paper.

In terms of the chemical properties of pollutants, most of the physical and chemical properties of clay come from the silicate layer morphology and particles less than $2 \mathrm{~nm}$, as well as the charge on the structure layer, so they can adsorb ions and interact with heavy metals [35]. When clay interacts with chemicals, the clay particles disperse, resulting in significant changes to the geotechnical properties of clay [36]. When the cation exchange capacity and cation concentration are changed, the arrangement of the soil particles will also be changed; thus, the pore size and distribution will be changed [37]. The forms of zinc in polluted soil include free ion $\left(\mathrm{Zn}^{2+}\right)$, zinc carbonate $\left(\mathrm{ZnCO}_{3}\right)$, zinc sulfate $\left(\mathrm{ZnSO}_{4}\right)$, zinc sulfide $(\mathrm{ZnS})$, and zinc complexes [38]. Zinc sulfate is a strong acid and weak base salt. After adding water, the zinc ion reacts with $\mathrm{OH}^{-}$to form amphoteric hydroxide zinc hydroxide, and a large amount of $\mathrm{H}^{+}$ions are left to produce a weakly acidic zinc sulfate solution. Zinc hydroxide dissolves in acid to form zinc salt and dissolves in alkali to form zincate. Acidic and alkaline liquids can react with clay minerals, dissolve clay mineral particles, reduce clay content, increase effective pore space, and weaken the connection between soil particles. From the analysis results of scanning electron microscopy and mercury injection tests, it can be found that the pore volume of soil increases and the structure becomes loose after the addition of zinc sulfate. Nayak et al. [39] also found that the structure of soil samples polluted by acid leachate showed aggregation, and the aggregation structure increased the effective pore space of soil. When the concentration of zinc sulfate in soil is increased, the salt content in pore water increases, zinc ion is further hydrolyzed, and the formation of clay particle flocculation leads to an increase in pore volume and the spacing of soil particles. As a result, the stability of stable soil is reduced. In addition, high concentrations of sulfate in soil may be harmful and lead to swelling and cracking of the soil [40]. Because the addition of a high content of zinc sulfate in soil will produce sulfate crystallization, crystallization between soil particles will produce pressure on the soil particles, increase the pore volume but also cause the soil particles to be broken into small particles as a result of expansion, destroying its original structure and weakening the cohesion between the soil particles. However, after increasing the concentration of zinc ions, zinc ions combine with calcium ions to form calcium zinc hydrate $\mathrm{CaZn}(\mathrm{OH})$ $\mathrm{H}_{2} \mathrm{O}$, which can form a barrier between soil particles [41]. It may also destroy the cementation of calcium ions in soil and reduce the strength of the soil.

In summary, zinc sulfate changes the mineral and chemical composition of red clay, weakens the cementation force and chemical bond force between soil particles, 
destroys the original structure of red clay, and causes an increase in the pore volume and fractal dimension of red clay. The increase of the fractal dimension and the deterioration of the structural stability lead to the weakening of the mechanical properties of red clay.

\section{Conclusions}

(1) With the increase in confining pressure, the shear strength increases gradually, and the variation in shear strength with concentration is roughly the same under different confining pressures. Under the same confining pressure, as the zinc ion concentration increases, the shear strength and cohesion decrease gradually, and there is a certain limit value. The angle of internal friction first increases and then decreases.

(2) The main mineral components of red clay are quartz, kaolinite, montmorillonite, and hematite. After adding zinc ions, only the quartz and kaolinite are left in the mineral composition, and the semiquantitative results increase. With the increase in zinc ion concentration, the semiquantitative quartz amount increases, and the semiquantitative kaolinite amount is reduced. The composition of $\mathrm{SiO}_{2}, \mathrm{Al}_{2} \mathrm{O}_{3}$, and $\mathrm{Fe}_{2} \mathrm{O}_{3}$ in red clay is as high as $87.195 \%$. As the zinc ion concentration increases, the $\mathrm{SiO}_{2}, \mathrm{Fe}_{2} \mathrm{O}_{3}$, $\mathrm{Na}_{2} \mathrm{O}$, and $\mathrm{CaO}$ contents gradually decrease, and the $\mathrm{Al}_{2} \mathrm{O}_{3}, \mathrm{TiO}_{2}$, and $\mathrm{K}_{2} \mathrm{O}$ contents first increase and then decrease.

(3) The red clay granules are mainly composed of laminated structures such as laths and block elements. Fewer fractures and micropores exist in the soil structure than when the clay contains zinc ions. After adding zinc ions, the contact between the particles changes from surface contact to point contact. The structural skeleton is constructed with loose interparticle connections due to the existence of pores. According to the MATLAB analysis, as the concentration of zinc ions increases, the porosity and fractal dimension of red clay increase, and the pore area and dispersion increase. The surface of the soil particles is rough, and the structural stability is weakened.

(4) The pore size distribution of red clay obtained by the mercury intrusion test is relatively uniform, mainly concentrated in small voids of $0.007 \mu \mathrm{m}<d<0.1 \mu \mathrm{m}$ and large pores of $1 \mu \mathrm{m}<d<10 \mu \mathrm{m}$. After adding zinc ions, the peak shape and position of the large and small pores of the red clay do not change much, but the large voids decrease. As the concentration of zinc ions increases, the number of pores first decreases, then increases, and finally decreases.

\section{Data Availability}

The data used to support the findings of this study are included within the article.

\section{Conflicts of Interest}

The authors declare that they have no conflicts of interest.

\section{Acknowledgments}

This project was financially supported by the National Key Research and Development Project (2017YFC1503102) and the National Natural Science Foundation of China (Grants nos. 51874065, and U1903112).

\section{References}

[1] X. Wei, H. Ji, S. Wang, H. Chu, and C. Song, "The formation of representative lateritic weathering covers in south-central Guangxi (southern China)," Catena, vol. 118, pp. 55-72, 2014.

[2] B. C. Liu, C. J. Li, Z. Y. Pan, and B. H. Zhang, "Laboratory test for mechanical properties of guilin red clay mixed with cement," Journal of Engineering Geology, vol. 20, no. 4, pp. 633-638, 2012.

[3] E. Mengue, H. Mroueh, L. Lancelot, and R. Medjo Eko, "Evaluation of the compressibility and compressive strength of a compacted cement treated laterite soil for road application," Geotechnical and Geological Engineering, vol. 36, no. 6, pp. 3831-3856, 2018.

[4] M. K. Gupta, A. K. Singh, and R. K. Srivastava, "Kinetic sorption studies of heavy metal contamination on Indian expansive soil," E-Journal of Chemistry, vol. 6, no. 4, pp. 1125-1132, 2009.

[5] A. C. F. De Vasconcelos, "Bentonite application in the remediation of copper contaminated soil," African Journal of Agricultural Research, vol. 11, no. 14, pp. 1218-1226, 2016.

[6] A. M. Awad, S. M. Shaikh, R. Jalab et al., "Adsorption of organic pollutants by natural and modified clays: a comprehensive review," Separation and Purification Technology, vol. 228, Article ID 115719, 2019.

[7] K. G. Bhattacharyya and S. S. Gupta, "Adsorption of a few heavy metals on natural and modified kaolinite and montmorillonite: a review," Advances in Colloid and Interface Science, vol. 140, no. 2, pp. 114-131, 2008.

[8] H.-Q. Zhang, Y.-Y. Yang, and Y.-C. Yi, "Effect of sulfate erosion on strength and leaching characteristic of stabilized heavy metal contaminated red clay," Transactions of Nonferrous Metals Society of China, vol. 27, no. 3, pp. 666-675, 2017.

[9] Y. Li, H. Zhang, C. Tu, F. Song, and Y. Luo, "Occurrence of red clay horizon in soil profiles of the yellow river delta: implications for accumulation of heavy metals," Journal of Geochemical Exploration, vol. 176, pp. 120-127, 2017.

[10] J. J. C. Bocanegra, E. E. Mora, and G. I. C. González, “Galvanic sludges: effectiveness of red clay ceramics in the retention of heavy metals and effects on their technical properties," Environmental Technology \& Innovation, vol. 16, Article ID 100459, 2019.

[11] L. Agwaramgbo, E. Agwaramgbo, C. Mercadel, S. Edwards, and E. Buckles, "Lead remediation of contaminated water by charcoal, LA red clay, spinach, and mustard green," Journal of Environmental Protection, vol. 2, no. 9, pp. 1240-1244, 2011.

[12] A. Gładysz-Płaska, M. Majdan, S. Pikus, and D. Sternik, "Simultaneous adsorption of chromium (VI) and phenol on natural red clay modified by HDTMA," Chemical Engineering Journal, vol. 179, pp. 140-150, 2012. 
[13] A. Gładysz-Płaska, E. Grabias, and M. Majdan, "Simultaneous adsorption of uranium (VI) and phosphate on red clay," Progress in Nuclear Energy, vol. 104, pp. 150-159, 2018.

[14] A. R. Goodarzi and H. R. Akbari, "Assessing the anion type effect on the hydro-mechanical properties of smectite from macro and micro-structure aspects," Geomechanics and Engineering, vol. 7, no. 2, pp. 183-200, 2014.

[15] Nanjing Institute of Water Resources Research, GB/T 501231999 Standard for Geotechnical Test Methods, China Planning Publishing House, Beijing, China, 1999.

[16] D. Hradil, J. Hradilová, P. Bezdička, and S. Svarcová, "Provenance study of gothic paintings from north-east Slovakia by handheld X-ray fluorescence, microscopy and X-ray microdiffraction," X-Ray Spectrometry, vol. 37, no. 4, pp. 376-382, 2008.

[17] E. W. Washburn, "Note on a method of determining the distribution of pore sizes in a porous material," Proceedings of the National Academy of Sciences of the United States of America, vol. 7, no. 4, pp. 115-116, 1921.

[18] M. Šebesta, L. Nemček, M. Urík et al., "Partitioning and stability of ionic, nano-and microsized zinc in natural soil suspensions," Science of the Total Environment, vol. 700, Article ID 134445, 2020.

[19] S. Hamidi and S. M. Marandi, "Clay concrete and effect of clay minerals types on stabilized soft clay soils by epoxy resin," Applied Clay Science, vol. 151, pp. 92-101, 2018.

[20] A. K. Jha and P. V. Sivapullaiah, "Mechanism of improvement in the strength and volume change behavior of lime stabilized soil," Engineering Geology, vol. 198, pp. 53-64, 2015.

[21] M. K. Uddin, "A review on the adsorption of heavy metals by clay minerals, with special focus on the past decade," Chemical Engineering Journal, vol. 308, pp. 438-462, 2017.

[22] K. Heister, "How accessible is the specific surface area of minerals? a comparative study with al-containing minerals as model substances," Geoderma, vol. 263, pp. 8-15, 2016.

[23] E. F. Covelo, J. M. Matías, F. A. Vega, M. J. Reigosa, and M. L. Andrade, "A tree regression analysis of factors determining the sorption and retention of heavy metals by soil," Geoderma, vol. 147, no. 1, pp. 75-85, 2008.

[24] J. Z. Wang, "The effects of free iron oxides on the engineering properties of red clay," Chinese Journal of Geotechnical Engineering, vol. 5, no. 1, pp. 147-156, 1983.

[25] C.-L. Jiang, J.-M. Séquaris, H. Vereecken, and E. Klumpp, "Effects of inorganic and organic anions on the stability of illite and quartz soil colloids in $\mathrm{Na}-\mathrm{Ca}$ - and mixed $\mathrm{Na}-\mathrm{Ca}$ systems," Colloids and Surfaces A: Physicochemical and Engineering Aspects, vol. 415, pp. 134-141, 2012.

[26] Z. Y. Chen, J. X. Zhou, and H. J. Wang, Soil Mechanics, Tsinghua University Press, Beijing, China, 1992.

[27] L. W. Kong, H. X. Luo, and J. X. Yuan, "Preliminary study on the effective cementation characteristics of the red clay," Chinese Journal of Geotechnical Engineering, vol. 17, no. 5, pp. 42-47, 1995.

[28] X. W. Zhang and L. W. Kong, "Interaction between iron oxide colloids and clay minerals and its effect on properties of clay," Chinese Journal of Geotechnical Engineering, vol. 36, no. 1, pp. 65-74, 2014.

[29] L. W. Kong and H. X. Luo, "Effect of the conversion in form of free iron oxide on the engineering property of the red clay," Rock \& Soil Mechanics, vol. 14, no. 4, pp. 25-39, 1993.

[30] H. D. Sharma and S. P. Lewis, Waste Containment Systems, Waste Stabilization, and Landfills: Design and Evaluation, John Wiley \& Sons, Hoboken, NJ, USA, 1994.
[31] J. J. Bowders and D. E. Daniel, "Hydraulic conductivity of compacted clay to dilute organic chemicals," Journal of Geotechnical Engineering, vol. 113, no. 12, pp. 1432-1448, 1987.

[32] C. D. Shackelford, C. H. Benson, T. Katsumi, T. B. Edil, and L. Lin, "Evaluating the hydraulic conductivity of GCLs permeated with non-standard liquids," Geotextiles and Geomembranes, vol. 18, no. 2-4, pp. 133-161, 2000.

[33] A. R. Goodarzi and M. Movahedrad, "Stabilization/solidification of zinc-contaminated kaolin clay using ground granulated blast-furnace slag and different types of activators," Applied Geochemistry, vol. 81, pp. 155-165, 2017.

[34] J. Wang, X. Lv, X. L. Qu, C. L. Zhong, and Y. L. Zhang, "Analysis of relationship between subgrade soil shear strength and chemical and minerals component," Journal of Jilin University, vol. 49, no. 3, pp. 766-772, 2019.

[35] G. Zhang, Y. Lin, and M. Wang, "Remediation of copper polluted red soils with clay materials," Journal of Environmental Sciences, vol. 23, no. 3, pp. 461-467, 2011.

[36] S. N. Rao and P. K. Mathew, "Effects of exchangeable cations on hydraulic conductivity of a marine clay," Clays and Clay Minerals, vol. 43, no. 4, pp. 433-437, 1995.

[37] R. N. Yong and B. P. Warkentin, Developments in Geotechnical Engineering, Soil Properties and Behaviour, pp. 1-449, Elsevier, Amsterdam, Netherlands, 1975.

[38] S. Paria and P. K. Yuet, "Solidification-stabilization of organic and inorganic contaminants using portland cement: a literature review," Environmental Reviews, vol. 14, no. 4, pp. 217-255, 2006.

[39] S. Nayak, B. M. Sunil, and S. Shrihari, "Hydraulic and compaction characteristics of leachate-contaminated lateritic soil," Engineering Geology, vol. 94, no. 3, pp. 137-144, 2007.

[40] L. Saussaye, M. Boutouil, F. Baraud, and L. Leleyter, "Soils treatment with hydraulic binders: physicochemical and geotechnical investigations of a chemical disturbance," in Proceedings of the ISSMGE-TC 211 International Symposium on Ground Improvement IS-GI, pp. 479-489, Brussels, Belgium, May 2012.

[41] I. W. Hamilton and N. M. Sammes, "Encapsulation of steel foundry bag house dusts in cement mortar," Cement and Concrete Research, vol. 29, no. 1, pp. 55-61, 1999. 